\title{
Stimulation of tumour growth by wound-derived growth factors
}

\author{
R Abramovitch, M Marikovsky ${ }^{*}$, G Meir and M Neeman \\ Department of Biological Regulation, The Weizmann Institute of Science, Rehovot 76100, Israel
}

\begin{abstract}
Summar $\mathbf{y T h e}$ goal of this work was to determine the molecular basis for the induction of tumour vascularization and progression by injury. Magnetic resonance imaging (MRI) studies demonstrated that administration of wound fluid derived from cutaneous injuries in pigs reduced the lag for vascularization and initiation of growth of $\mathrm{C} 6$ glioma spheroids, implanted in nude mice, and accelerated tumour doubling time. The former effect can be attributed to the angiogenic capacity of wound fluid as detected in vivo by MRI, and in vitro in promoting endothelial cell proliferation. The latter effect, namely the induced rate of tumour growth, is consistent with the angiogenic activity of wound fluid as well as with the finding that wound fluid was directly mitogenic to the tumour cells, and accelerated growth of C6 glioma in spheroid culture. Of the multiple growth factors present in wound fluid, two key factors, heparin-binding epidermal growth factor (EGF)-like growth factor (HB-EGF) and platelet-derived growth factor (PDGF), were identified as the dominant mitogens for C6 glioma, and inhibition of their activity using specific neutralizing antibodies suppressed the mitogenic effect of wound fluid on DNA synthesis in C6 glioma. This study suggests that the stimulatory effect of injury on tumour progression can possibly be attenuated by therapeutic targeting directed against a limited number of specific growth factors.
\end{abstract}

Keywords: heparin-binding epidermal growth factor; magnetic resonance imaging; C6 glioma spheroid; tumour growth; angiogenesis

The increased probability of recurrence and accelerated tumour growth in the location of tissue injury are common clinical complications associated with the invasive procedures frequently used in cancer therap y. The concept that injuries promote tumour development at the injured site was suggested already in 1927 (Deelman, 1927). This concept was extended to show that trauma increased the probability of tumour formation in the injured o rgan, withou affecting the distribution to other sites, by promoting implantation and proliferation of circulating cancer cells (Murthy et al, 1991). The tumours specifically developed in traumatized o rgans in injury site, and as the wounds heal their ability to facilitate implantation and/or growth of tumour cells decreases (Murthy et al, 1989). It seems that the same repair processes involved in wound healing also contribute to tumour attachment and growth (Dvorak et al, 1995). We showed previously that injured skin tissue provides a favourable milieu for the neovascularization and growth of C6 glioma spheroids, implanted subcutaneously in nude mice (Abramovitch et al, 199 a\$. Moreove r, we showed that the presence of microtumours in an injured tissue inhibited the healing process, leaving an open persistent wound. O'Reilly et al (1994, 1996) showed recently that excision of a primary tumour accelerates the growth of a secondary tumour and metastases in other organs. This acceleration of tumour growth has been attributed to the removal of primary tumou r-generated inhibitory factors. Howeve $r$, recent studies have shown that su rgical wounding of normal tissues significantly stimulated the growth of malignant tissues without the concomitant excision of a tumour mass
(Bogden et al, 1997). This humoral stimulating e ffect was not histologically specific or species specific (Bogden et al, 1997).

The process of healing and repair of damaged tissue is highly regulated by a la rge number of specific soluble growth factors which are released within the wound environment and which appear to induce neovascularization, inflammation, cell proliferation and deposition of collagen and other extracellular matrix molecules within the wound. These events are stimulated and regulated by mitogens and chemotactic factors which are secreted thefrom cells in the wound border and from inflammatory cells (Lynch, 1991; Frank et al, 1995; Moulin, 1995). It appears that the same mediators of cell growth and stromal synthesis are involved in malignanc y, fetal growth and wound healing. Many growth factors are released during tissue repai $r$, and some of them such as fibroblast growth factors (FGFs), transforming growth facto $\alpha \mathrm{r}$ (TGF $-\alpha$ ), epidermal growth factor (EGF), platelet-derived growth factor (PDGF), vascular endothelial growth factor (VEGF), tumour necrosis facto $\alpha$ (TNF- $\alpha)$, TGF $\beta$ and heparin-binding epidermal growth facto r-like growth factor (HB-EGF) have been shown to be angiogenic in vivo ( Lynch, 1991; Moulin, 1995; Abramovitch et al, 1998b). In addition, many of these growth factors are known to be directly mitogenic to tumour cells. It was shown previously that EG F, PDGF-BB and other growth factors a ffect glioma spheroids growth, migration and invasion (Pedersen ofet al, 1994). An additional enhancing mechanism could be the induction of VEGF secretion in the tumour as a result of exposure to growth factors released from the wound. It was recently shown 
that VEGF secretion was induced in glioma cells by physiological concentrations of EGF, PDGF-BB and basic fibroblast growth factor (bFGF) (Tsai et al, 1995).

In light of the complexity of wound healing and the multiple cell types and growth factors involved, it is of interest to determine whether the stimulatory effects of injuries on tumour progression can be attributed to a restricted repertoire of molecules whose activity could possibly be antagonized.

The goal of this study was to identify the key growth factors that are found in healing wounds and exert a major stimulatory effect on tumour growth. In order to study the molecular basis for this stimulatory effect, we developed an experimental model using wound fluid derived from a cutaneous wound in pig (Marikovsky et al, 1993) and injected locally to an implanted C6 glioma spheroid. Using this system, we could reproduce the stimulatory effects of the wound on tumour progression, and could analyse the active constituents present in the wound. We show here that wound fluid collected during the first 3 days of pig injury enhances tumour growth in vivo, that wound fluid is angiogenic in vivo and mitogenic to bovine endothelial cells in vitro, and that wound fluid is directly mitogenic to C6 glioma cells. HB-EGF and PDGF were previously shown to be the major heparin-binding growth factors present in wound fluid (Marikovsky et al, 1993). Moreover, we have recently demonstrated that HB-EGF is angiogenic in vivo and induces VEGF expression in vascular smooth muscle cells (Abramovitch et al, 1998b). Here, we demonstrate that in wound fluid HB-EGF and PDGF are the major mitogens for C6 glioma cells.

\section{MATERIALS AND METHODS}

\section{Materials}

Human PDGF-BB and neutralizing anti-human PDGF antibodies were purchased from Collaborative Biomedical Products (Bedford, MA, USA). Recombinant HB-EGF and neutralizing anti-human HB-EGF polyclonal antibody 197 were kindly provided by Dr Judith A Abraham (Scios Nova, Mountain View, CA, USA). Neutralizing anti-HB-EGF polyclonal antibody 197 was raised in goats, directed against recombinant 77-amino-acid human HB-EGF. Antibodies were incubated with the wound fluid for $16 \mathrm{~h}\left(20 \mu \mathrm{g} \mathrm{ml}^{-1}, 4^{\circ} \mathrm{C}\right)$ and then added to cells. The antibodies are specific and do not interact with either EGF, TGF- $\alpha$ or amphiregulin. Pig plasma (Sigma) was used as a control for the effect of wound fluid.

\section{Cell culture and spheroid preparation}

C6 rat glioma cells were routinely cultured in DMEM (Dulbecco's modified Eagle medium) supplemented with 5\% fetal calf serum (FCS, Biological Industries, Israel), penicillin (50 unit $\mathrm{ml}^{-1}$ ), streptomycin $\left(50 \mu \mathrm{g} \mathrm{ml}^{-1}\right)$ and fungizone $\left(125 \mu \mathrm{g} \mathrm{ml}^{-1}\right)$ (Biolab). Aggregation of cells into small spheroids of about $150 \mu \mathrm{m}$ was initiated in agar-coated bacteriological plates. After 4-5 days in culture, the spheroid suspension was transferred to a $250-\mathrm{ml}$ spinner flask (Bellco, USA) and the medium changed every other day for approximately 6 weeks. Other parameters of spheroid culture were as reported previously (Abramovitch et al, 1995, $1998 c)$.

\section{Spheroid growth kinetics}

Spheroids used for growth measurements were cultured individually in 24-well plates (Nunc, Denmark) coated with agar. An overlay suspension of $0.5 \mathrm{ml}$ DMEM with the corresponding growth factor $\left(1 \mathrm{ng} \mathrm{ml}^{-1}\right)$ was added. Spheroid diameter was measured daily using a microscope with a calibrated reticle in the eyepiece. The spheroid volume was calculated from the diameter measurements (four spheroids per treatment).

\section{Spheroid implantation in nude mice}

Male CD1-nude mice ( 2 months old, $30 \mathrm{~g}$ body weight) were anaesthetized with a single dose of $75 \mu \mathrm{g} \mathrm{\textrm {g } ^ { - 1 }}$ ketamine plus $3 \mu \mathrm{g} \mathrm{g}^{-1}$ xylazine (i.p.) and placed in a sterile laminar flow hood. A single spheroid per mouse (approximately $1 \mathrm{~mm}$ in diameter) was implanted subcutaneously in the lower back through a 4-mm incision as reported previously (Abramovitch et al, 1995). The incision was formed by fine surgical scissors and closed with cyanoacrylate (Super Glue-3, Loctite, Ireland).

\section{Wound fluid preparation}

Wound fluid (WF) was derived from injured pigs at various days after injury as reported previously (Marikovsky et al, 1993). Briefly, medium partial-thickness excisional wounds $(15 \times 15 \times$ $1.2 \mathrm{~mm}$ ) were created on the back of female Large White $x$ Landraei pigs (40 kg). Each wound was covered with a liquid-tight vinyl chamber filled with $1.2 \mathrm{ml}$ of normal saline containing

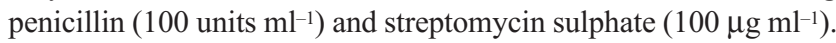
The solution from all wounds was pooled daily after injury, centrifuged, filtered through $0.45-\mu \mathrm{m}$ filters and frozen at $-20^{\circ} \mathrm{C}$. Control solutions consisted of saline, penicillin (100 units $\mathrm{ml}^{-1}$ ) and streptomycin sulphate $\left(100 \mu \mathrm{g} \mathrm{ml}^{-1}\right)$.

\section{Wound fluid injections to tumour-bearing mice}

WF derived from injured pigs (first 2 days after injury) was injected in mice in which a spheroid was implanted more than $1 \mathrm{~cm}$ away from the incision (subcutaneous injections began with spheroid implantation and continued every 2-3 days, close to the implanted spheroid). Control animals were injected with saline or with phosphate-buffered saline (PBS) supplemented with antibiotics or with pig plasma.

\section{Analysis of the angiogenic activity of wound fluid}

Spherical agarose beads of approximately $1 \mathrm{~mm}$ in diameter were formed from $4 \%$ low gelling temperature agarose (Sigma) with either phosphate-buffered saline (PBS) or basic fibroblast growth factor (b-FGF; 0.5 or $5 \mu \mathrm{g}$ ), pig plasma or WF (fourfold concentrated). The tested compounds ( $5 \mu 1$ per bead) were warmed to $38^{\circ} \mathrm{C}$ by placing them for a few seconds in sterile micro test tubes in a dry bath. Agarose solution $\left(6 \%\right.$ in saline, $\left.45^{\circ} \mathrm{C}\right)$ was then added (10 $\mu 1$ per bead), and beads were formed above ice using a $20-\mu$ pipette tip. Beads were implanted in nude mice $1 \mathrm{~cm}$ from the incision site, one bead per mouse. All control beads contained antibiotics as in the wound fluid (penicillin, 100 units $\mathrm{ml}^{-1}$ and streptomycin sulphate, $100 \mu \mathrm{g} \mathrm{ml}^{-1}$ ). 


\section{Magnetic resonance imaging (MRI) of the implanted spheroids or beads}

MRI experiments were performed on a horizontal 4.7 T BrukerBiospec spectrometer using a 2-cm surface coil. Mice were anaesthetized with a single dose of $75 \mu \mathrm{g} \mathrm{g}^{-1}$ ketamine plus $3 \mu \mathrm{g} \mathrm{g}^{-1}$ xylazine (i.p.), and placed supine with the tumour located at the centre of the surface coil. Gradient echo images (slice thickness of $0.5-0.6 \mathrm{~mm}$, TR $100 \mathrm{~ms}, 256 \times 256$ pixels, in plane resolution of $110 \mu \mathrm{m})$ were acquired with echo time of $20 \mathrm{~ms}$. Growth of the capillary bed was reflected by reduction of the mean intensity at a region of interest of $1 \mathrm{~mm}$ surrounding the spheroid or the agarose bead (Abramovitch et al, 1995, 1998a,c; Schiffenbauer et al, 1997). Data is reported here as the apparent vessel density $\left[\mathrm{AVD}_{\mathrm{MRI}}=-\ln S(\mathrm{a}) / S(0)\right]$, in which $S(\mathrm{a})$ is the mean intensity at a region of interest of $1 \mathrm{~mm}$ surrounding the spheroid or the agarose bead and $S(0)$ is the mean intensity of a distant muscle. Angiogenic capacity of the implanted beads was evaluated from the difference between $\mathrm{AVD}_{\mathrm{MRI}}$ on day 4 and $\mathrm{AVD}_{\mathrm{MRI}}$ on day 1 after implantation:

$$
\Delta_{\mathrm{AVD}}=\mathrm{AVD}_{\mathrm{MRI}}(\text { day } 4)-\mathrm{AVD}_{\mathrm{MRI}}(\text { day } 1)
$$

Tumour volume was determined from two orthogonal sets of multislice gradient echo images covering the entire tumour, as reported previously (Abramovitch et al, 1995, 1998a).

MRI data was analysed on a Personal Iris work station (Silicon Graphics, USA) with software from NMRi (Tripos). Statistical significance of treatments was determined using Student's $t$-test or ANOVA. Errors reported are the standard deviation.

\section{Measurement of DNA synthesis}

C6 rat glioma cells were plated in 96-well plates (Nunc, Denmark) (5000 cells per well) in DMEM with 5\% FCS. After $6 \mathrm{~h}$, the cells were rinsed and incubated for $48 \mathrm{~h}$ in serum-free medium. Wound fluid, pig plasma or growth factors were then added for $24 \mathrm{~h}$ (triplicates). $\left[{ }^{3} \mathrm{H}\right]$ thymidine $5 \mu \mathrm{Ci} \mathrm{m}^{-1}$ (Rotem Industries, Israel) was added to the cells for the last $14 \mathrm{~h}(10 \mu \mathrm{l})$. The cells were rinsed with $100 \mu \mathrm{l}$ methanol for $10 \mathrm{~min}$, followed by $200 \mu 15 \%$ cold trichloroacetic acid. Afterwards, cells were washed with water and lysed with $150 \mu 10.5 \mathrm{M}$ sodium hydroxide. Radioactive thymidine incorporation into DNA was determined for $60 \mathrm{~s}$ with $3 \mathrm{ml}$ scintillation liquid (Ultima Gold, Packard) in a liquid scintillation $\beta$-counter.
Brain bovine capillary endothelial cells $(\mathrm{BBCE})$ were plated in 24-well plates (6000 cells per well) in $500 \mu 1$ medium [low glucose DMEM $\left(\mathrm{g}^{-1}\right)+10 \%$ Colorado calf serum (CS) (Gibco, USA) and antibiotics: penicillin (100 units $\left.\mathrm{ml}^{-1}\right)$, streptomycin (100 $\left.\mu \mathrm{g} \mathrm{m}^{-1}\right), 2 \mathrm{~mm}$ glutamine (Biolab, Israel) (PSG).

After $24 \mathrm{~h}$, the medium was changed to serum starvation medium ( $2 \% \mathrm{CS}, 0.5 \% \mathrm{BSA}$, and PSG) for $24 \mathrm{~h}$ in the presence of wound fluid or wound fluid-derived growth factors. $\left[{ }^{3} \mathrm{H}\right]$ thymidine $(0.6 \mu \mathrm{Ci})$ was added for the last $6 \mathrm{~h}$. DNA synthesis assays (duplicates) were performed as described above.

All values were scaled by the counts from the respective control samples that were exposed to serum starvation medium alone.

\section{Histology}

Skin with tumour specimens were fixed in neutral buffer formaldehyde $(\mathrm{pH}=7)$ for $24 \mathrm{~h}$, washed in $70 \%$ ethanol, embedded in paraffin, sectioned and stained with light green (Masson), eosin and haematoxylin.

\section{RESULTS}

\section{Exogenous wound fluid promotes tumour neovascularization and growth}

The stimulatory effects of wounds on tumour growth are clearly evident for in situ wounds on C6 glioma tumours implanted in nude mice (Abramovitch et al, 1998a). Unfortunately, the minute amounts of growth factors released in these in situ wounds do not allow for molecular analysis of the role of the different growth factors. To elucidate this point, we resorted to a more complex experimental system. The stimulatory effect of the wound on tumour progression was studied here using wound fluid (WF) derived from a pig wound model. The first step in this project was to test whether WF stimulated vascularization of implanted spheroids and accelerated tumour growth, as observed previously for in situ dermal incisions (Abramovitch et al, 1998a). Wound fluid was derived from partial thickness excisional wounds created on the back of a pig as reported previously (Marikovsky et al, 1993), and was injected subcutaneously next to an implanted C6 glioma spheroid (Figure 1). Control mice were injected with PBS $(n=9)$ or with pig plasma $(n=2)$. Wound fluid administration was initiated
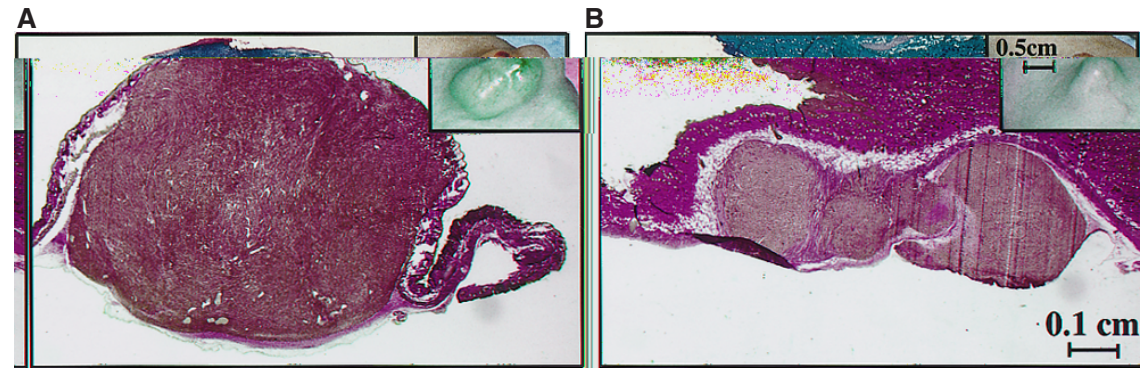

Figure 1 Wound fluid enhances tumour growth for C6 glioma spheroids implanted in nude mice. (A and B) Histological sections of C6 glioma tumours 21 days after implantation (bar, $0.1 \mathrm{~cm}$ ). Mice were injected with a total amount of $2.4 \mathrm{ml}$ of either wound fluid derived from day 2 of pig injury (A) or PBS (B); subcutaneous injections, close to the implanted spheroid, eight injections of $300 \mu$ l each every 2-3 days starting on the day of spheroid implantation. Tumour treated with wound fluid showed a significant effect through the entire experiment and tumour volume was fourfold larger at the end of the experiment. Inserts, photographs of the same tumours as in $\mathbf{A}$ and $\mathbf{B}($ bar, $0.5 \mathrm{~cm})$ 


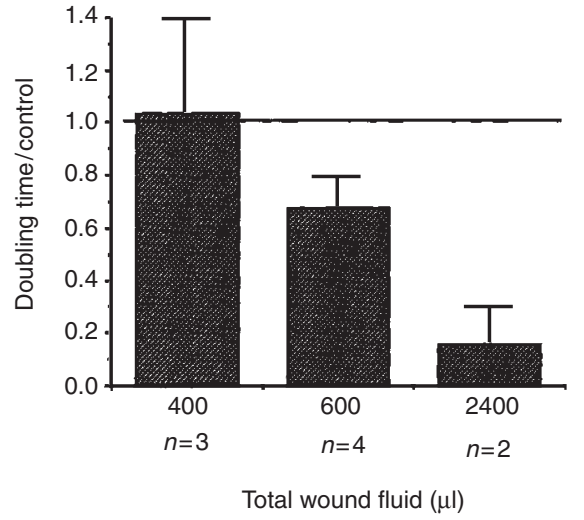

Figure 2 The effect of wound fluid derived from pig on the progression of C6 glioma tumours in nude mice. Tumour volume was determined every $2-3$ days by gradient echo MRI from two orthogonal sets of multislice images covering the entire tumour (Bruker Biospec spectrometer, 4.7 T; TE $=20 \mathrm{ms,}$ $\mathrm{TR}=100 \mathrm{~ms}, 0.11 \mathrm{~mm}$ in plane resolution; $0.5-0.6 \mathrm{~mm}$ slice thickness). Wound fluid reduced tumour doubling time for $\mathrm{C} 6$ glioma tumours in vivo in a dose-dependent manner on the 3rd week after implantation. WF derived from injured pigs (days 1-2) was injected into the mice subcutaneously, close to the implanted spheroid, every $2-3$ days. Control animals were injected with saline or pig plasma

at the time of spheroid implantation. Care was taken to position the spheroid at a distance larger than $1 \mathrm{~cm}$ from the incision so as to avoid direct stimulation of tumour growth by the in situ surgical wound (Abramovitch et al, 1998a).

As observed previously for spheroids implanted on a full thickness dermal incision, treatment with WF reduced the lag in tumour growth (from 5 days to 3 days; $n=5$ ), and the early stages of neovascularization were enhanced (vascular density was maximal on day 4 , relative to day 6 for control spheroids; $n=5$ ). In contrast to wound fluid, pig plasma and PBS did not induce tumour growth. The apparent vessel density $\left(\mathrm{AVD}_{\mathrm{MRI}}\right)$ was derived from gradient echo images of tumour treated with WF (6 injections, 100 $\mu$ leach, every 48 h) 8 days after implantation. Vessel density was much larger in WF-treated spheroids than that observed in control spheroids ( $0.964 \pm 0.19, n=5$, and $0.447 \pm 0.19, n=8$, respectively; $P=0.0003)$. Histological sections show that the enhanced rate of tumour growth can be attributed to the tumour cells themselves and not to infiltrating host cells such as fibroblasts (Figure 1).

In addition to the proangiogenic activity, WF also accelerated the rate of tumour growth. Tumour growth in WF-treated mice was monitored by MRI and was compared with the rate of tumour growth in control mice. For mice that were injected with a total amount of $0.4 \mathrm{ml}$ wound fluid (four injections of $100 \mu \mathrm{lWF}$ each, every $2-3$ days, $n=3$ ), the effect on tumour growth rate relative to control mice (four injections of $100 \mu$ l saline each, every 2-3 days, $n=3$ ) was evident during the first 4 days after spheroid implantation, but there was no observable effect on tumour development in the 3rd week of tumour growth (days 14-18) (Figure 2). For mice that were injected with a total amount of $0.6 \mathrm{ml}$ wound fluid (six injections of $100 \mu \mathrm{lWF}$ each, every $2-3$ days, $n=4)$, there was a $40 \%$ increase in growth rate (reduced doubling time) relative to control mice (six injections of $100 \mu 1$ saline each, every 2-3 days, $n=4$ ) observable in the 3rd week (days 14-18) (Figure 2). Mice injected with a higher dose of WF, i.e. a total amount of $2.4 \mathrm{ml}$ (eight injections of $300 \mu \mathrm{lWF}, n=2$ ), showed a significant effect

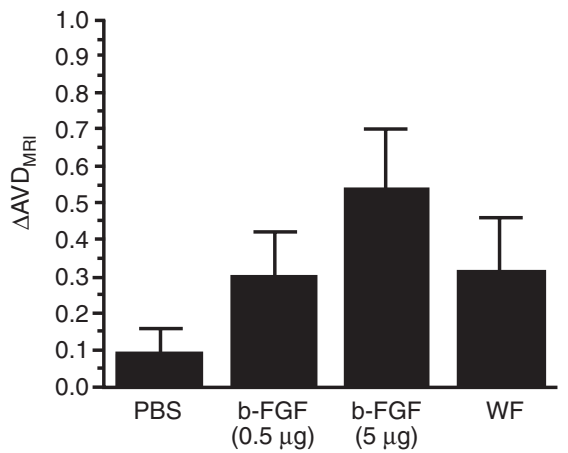

Figure 3 WF promotes neovascularization in vivo in beads implanted subcutaneously in nude mice. Agarose beads containing the various materials were implanted as described in Materials and methods. The angiogenic potential of WF in vivo is demonstrated quantitatively by MRI. The apparent vessel density (AVD ) was determined from the degree of signal loss in gradient echo MRI, as described previously (Abramovitch et al, 1995, 1998a; Schiffenbauer et al, 1997). Neovascularization around the beads was quantitatively evaluated by subtraction of the AVD ${ }_{\text {mRI }}$ measured on day 1 from the one measured on day 4 after implantation $\left(\triangle A V D_{M B}\right)$. PBS, as a negative control, did not induce neovascularization around the bead $(n=8)$, whereas bFGF, as a positive control, caused significant neovascularization around the beads ( $n=3$ and $n=7$ for 0.5 and $5 \mu \mathrm{g}$ bFGF respectively). In comparison, wound fluid (WF; $5 \mu \mathrm{l}$ ) from the first 3 days after injury induced significant neovascularization around the beads $(n=6)$

relative to control mice (eight injections of $300 \mu \mathrm{PBS}, n=2$, or $300 \mu \mathrm{l}$ pig plasma, $n=2$ ) through the entire experiment ( 3 weeks). Tumour doubling time in WF-treated mice was 6.7 times faster than control saline or plasma-treated mice on days 14-18 (Figure 2), and tumour volume measured by MRI was fourfold larger. The maximal volume of WF $(2.4 \mathrm{ml})$ is the amount of WF released during 1 day from a $2.5 \mathrm{~cm}^{2}$ partial thickness excisional wound in our experimental wound model in pig. These experiments suggest that the duration and dose of cumulative exposure to wound-derived factors affects the degree of tumour stimulation.

\section{Wound fluid is angiogenic}

The angiogenic capacity of WF was assayed in vivo by MRI. Agarose beads containing PBS, b-FGF or WF derived 1 day after injury were implanted subcutaneously in nude mice as reported

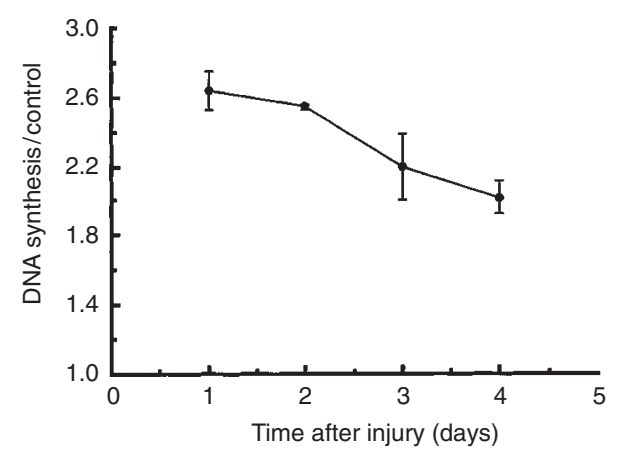

Figure 4 Wound fluid increases DNA synthesis in endothelial cells. The angiogenic potential of wound fluid in vitro was tested by $\left[{ }^{3} \mathrm{H}\right]$ thymidine incorporation into brain bovine capillary endothelial cells (BBCE) as described in Materials and methods. The angiogenic capacity of WF was maximal with WF derived 1 day after injury, and decreased slowly during the wound healing process 
previously (Abramovitch et al, 1995, 199 a)8 PBS, a negative control, did not cause neovascularization around the bead $\triangle_{\text {AVD }} \in$ $0.08 \pm 0.06 ; n=8$ ), whereas $\mathrm{b}-\mathrm{FG} \mathrm{F}$, a known angiogenic growth facto $r$, showed dose-dependent increase in the $\quad A \forall D)$ ((Figure 3 ). WF derived from injured pigs during the first 3 days after injury (fourfold concentrated) showed significant neovascularization around the beads $\left.\Delta_{A v D}=0.32 \pm 0.14 ; n=6\right)$, which was comparable to that observed for $0 . \mu g \mathrm{~b}-\mathrm{FGF} \Theta_{\mathrm{AVD}}=0.3 \pm 0.11$; $n=3$ ) and less than that of $\mu \mathrm{g}$ b-FGF $\Theta_{\text {AVD }}=0.54 \pm 0.2 ; n=7$ ) (Figure 3). The specificity of the e ffect of pig-derived WF was evaluated by comparison with pig plasma. In contrast to W implantation of an agarose bead containing pig plasma $n=4 \gamma \mathrm{did}$ not cause neovascularization around the bead.

In accord with the angiogenic capacity of WF in vivo, WF was mitogenic to endothelial cells in vitro (Figure 4). WF derived 1 day after pig injury showed the maximal enhancement of DNA synthesis $\left(\left[{ }^{3} \mathrm{H}\right]\right.$ thymidine incorporation) in bovine endothelial cells: 2.6-fold increase relative to control cells (Figure 4). This effect slowly decreased to twofold for WF derived 4 days after injury.

\section{Wound fluid enhances growth of C6 glioma in vitro}

The stimulatory e ffect of WF on the rate of tumour growth suggests that, in addition to its angiogenic activit also exerts a direct e ffect on the rate of tumour cell proliferation. To identify possible growth factors in WF which promote proliferation of C6 glioma cells, we studied the direct e ffect of growth factors known to be present in W F. Basic-FG F, HB-EGF and PDGF enhanced DNA synthesis in C6 glioma cells, as measured by thymidine incorporation, in monolayer cell culture (Figure $5 \mathrm{~A}$ ). Basic-FGF increased DNA synthesis by approximately 1.9-fold above control. The maximal e ffect was obtained at a concentration of $1 \mathrm{ng} \mathrm{ml} \mathrm{m}^{-1}$. HB-EGF increased DNA synthesis by 1.95 -fold over negative control, the maximal e ffect being obtained by $3 . \quad 3 \mathrm{ng} \mathrm{ml}$ FPDGF increased DNA synthesis by 1.74 -fold above control and the maximal e ffect was obtained by $3.3 \mathrm{ng}^{-1} \mathrm{ml}$

The e ffect of these growth factors on the growth of C6 glioma in three-dimensional spheroid culture was also studied (Figure 5B). Spheroid growth was significantly stimulated by $1 \mathrm{ng}^{-1} \mathrm{mdf}$ PDG F, EGF and HB-EGF (2.21- to 2.36-fold increased volume in 4 days) compared with control (1.49-fold increased volume) (Figure 5B). Basic-FGF had a, relativel y, smaller e ffect on spheroid growth (1.86-fold).

In view of the direct mitogenic activity of PDG F, EG F, HB-EGF and bFG F, we checked the e ffect of WF on C6 glioma cells. As expected, WF was indeed directly mitogenic to the C6 glioma tumour cells (Figure 6A). WF derived from the first 3 days after injury enhanced DNA synthesis in C6 glioma cells in a dose$\mathrm{y}$, WF possibly dependent manne r. WF from days 1-2 after injury increased DNA
A

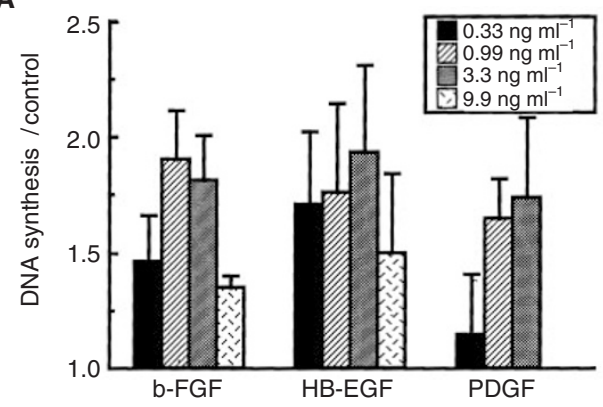

B

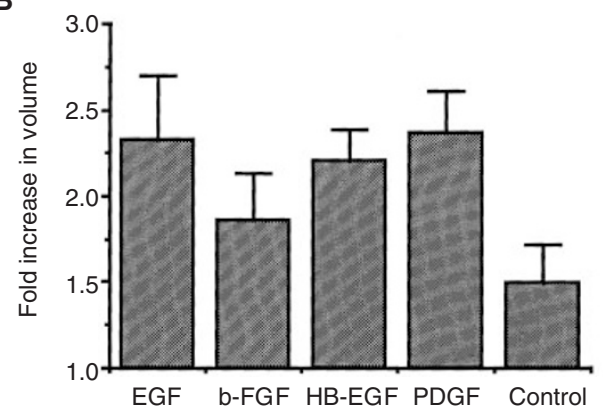

Figure 5 Growth factors associated with wound repair are mitogenic to $\mathrm{C} 6$ glioma. The mitogenic e ffect of growth factors was determined in vitro. (A) Basic-FG F, HB-EGF and PDG F, growth factors present in wound fluid during days 1-2, enhanced DNA synthesis in C6 glioma cells. B) Effect of growth factors on spheroid growth. PDG F, EGF and HB-EGF at $1 \mathrm{ng}^{1} \mathrm{ml}$ significantly enhanced $\mathrm{C} 6$ glioma spheroid growth in vitro. Spheroids were cultured individually on agar as described in Materials and methods. For each spheroid, the gain in volume after 4 days in culture was calculated (four spheroids per treatment)
A

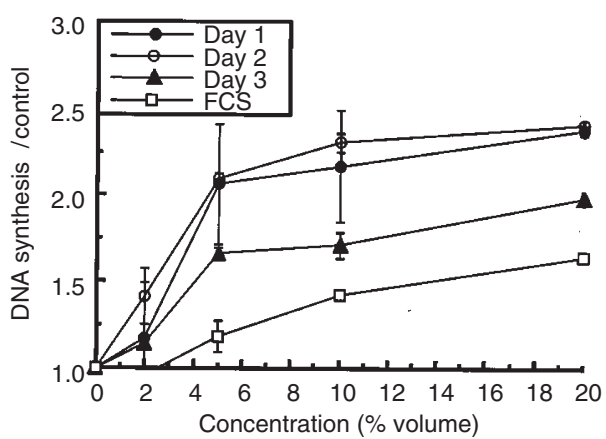

B

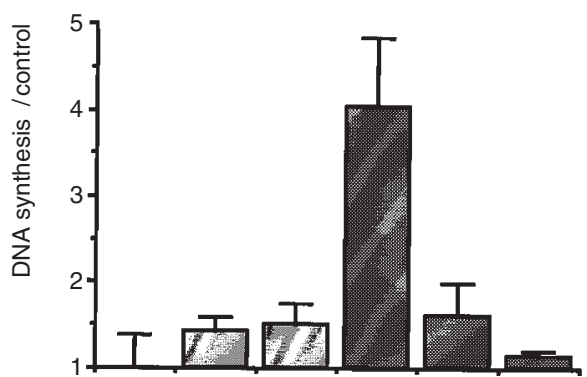

\begin{tabular}{l|c|c|c|c|c|c} 
Pig plasma & + & + & + & & & \\
\hline WF & & & & + & + & + \\
\hline Anti-PDGF antibody & & + & & & + & \\
\hline Anti-HB-EGF antibody & & & + & & & +
\end{tabular}

Figure 6 WF is mitogenic to $\mathrm{C} 6$ glioma cells. A)(The mitogenic activity of WF on $\mathrm{C} 6$ glioma cells in vitro was determined by $\left[{ }^{3} \mathrm{H}\right]$ thymidine incorporation. WF derived from the first 3 days after injury enhanced DNA synthesis in a dose-dependent manne B)(HB-EGF and PDGF are the main mitogens present in WF for $\mathrm{C} 6$ glioma cells. Neutralizing antibodies against either PDGF-BB or against HB-EGF blocked most of the enhancing e ffect of wound fluid derived 2 days after pig injur $\quad y$. Pig plasma had no e ffect on DNA synthesis in $\mathrm{C} 6$ glioma cells 
synthesis by approximately 2.4-fold above control. WF derived 3 days after injury increased DNA synthesis by twofold. WF was more mitogenic to C6 glioma than FCS. Pig plasma (10\%), in contrast, had no effect on thymidine incorporation in C6 glioma cells (Figure 6B).

With the demonstration that growth factors known to be present in WF can stimulate tumour cell proliferation, it was of interest to evaluate their role in the mitogenicity of WF for C6 glioma cells. This was carried out by antagonizing their activity in WF with neutralizing antibodies. Neutralizing antibodies against either PDGF-BB or HB-EGF blocked most of the mitogenic activity of WF derived 2 days after pig injury for $\mathrm{C} 6$ glioma in vitro (Figure $6 \mathrm{~B})$. WF derived 2 days after pig injury increased DNA synthesis in C6 glioma cells fourfold above control. Neutralizing antibodies against HB-EGF suppressed $95 \%$ of the mitogenic effect of WF and neutralizing antibodies against PDGF-BB suppressed $80 \%$ of the mitogenic effect of WF. Thus, a significant contribution to the direct mitogenic activity of WF on the tumour cells can be attributed to these two growth factors. In contrast to WF, pig plasma had no effect on DNA synthesis in C6 glioma cells (Figure 6B).

\section{DISCUSSION}

The increased probability of recurrence and accelerated tumour growth in the location of tissue injury are common clinical complications associated with the invasive procedures frequently used in cancer therapy. Understanding the fundamental principles that are involved may provide a way to possibly reduce the incidence and extent of tumour induction resulting from treatment. We have previously demonstrated that MRI can be used to follow primary tumour angiogenesis in vivo in a model system of an implanted multicellular spheroid (Abramovitch et al, 1995), as well as for monitoring the induction of spheroid neovascularization by proximal injury (Abramovitch et al, 1998a). In the study reported here, we applied quantitative MRI to measure the angiogenic properties of wound fluid as well as the stimulatory effect of wound fluid on the progression of implanted C6 glioma spheroids in vivo.

The phenomenon of tumour growth enhancement by injury was reproduced by injecting wound fluid (derived from injured pigs 1-2 days after wound formation) to tumour-bearing mice. Wound fluid stimulated DNA synthesis in endothelial cells, and accordingly increased vascularization in mouse skin by implanted agarose beads containing wound fluid. In addition, wound fluid showed direct mitogenic activity on C6 glioma cells. Thus, this approach made it possible to identify the growth factors which are known to participate in wound healing for their role and importance in the enhancement of tumour proliferation and vascularization resulting from injury. HB-EGF is a well-characterized $22-\mathrm{kDa}$ glycoprotein that binds the EGF receptor with high affinity and is mitogenic for fibroblasts, smooth muscle cells and epithelial cells (Higashiyama et al, 1991; Marikovsky et al, 1993). Both HB-EGF and PDGF were previously shown to be present in wound fluid (Marikovsky et al, 1993). Moreover, HB-EGF was shown to be the most prominent heparin-binding mitogen for fibroblasts (Marikovsky et al, 1993) and for epidermal keratinocytes (Marikovsky et al, 1996) during wound repair. Recently, we showed that HB-EGF is angiogenic in vivo, an activity which was attributed to expression and secretion of VEGF by HB-EGF-stimulated vascular smooth muscle cells (Abramovitch et al, 1998b).
In the study presented here, HB-EGF and PDGF were found to be the major mitogens for $\mathrm{C} 6$ glioma cells present in wound fluid. We suggest, therefore, that HB-EGF and PDGF are likely candidates for mediating the direct stimulatory effect of wounds on tumour progression. The fact that neutralization of either HB-EGF or PDGF inhibited almost all the induced mitogenic effect of wound fluid on C6 cells is in accord with the findings of a synergistic relation between these two growth factors (M Marikovsky and $\mathrm{M}$ Klagsbrun, unpublished data). A similar induction of proliferation of breast and ovarian cancer cells was recently reported for HB-EGF released in tumours by infiltrating T-cells (Peoples et al, 1995). In addition, it was shown previously that EGF, PDGF-BB and other growth factors affect glioma spheroids growth, migration and invasion (Pedersen et al, 1994). The important effect of PDGF is reinforced because it was shown that high-grade primary gliomas express increased levels of PDGF receptors, and the presence of PDGF receptors appears to correlate with tumour progression (Strawn et al, 1994). By using dominant negative PDGF- $\beta$ receptors, growth of $\mathrm{C} 6$ glioma could be inhibited both in vitro and in vivo. Glioma progression has also been correlated with amplification of the EGF receptor gene (Libermann et al, 1985).

The study reported here suggests that specific inhibition of the key growth factors in wound fluid could possibly be used to protect cancer patients undergoing surgical intervention from the tumour stimulatory effects of injury. However, the effect of neutralizing the activity of these growth factors, known to be important in wound healing, must first be carefully evaluated. Furthermore, the specific repertoire of dominant growth factors could be tumour specific and might be different for rat and human tumours, as reported previously for glioma cells lines (Pollack et al, 1991).

In summary, we demonstrate here that growth factors released in injury sites are directly mitogenic to tumour cells, leading to accelerated tumour growth. For C6 glioma cells, the major mitogenic activity was attributed to HB-EGF and PDGF. In addition, wound fluid contributes a significant angiogenic activity and thus could enhance the angiogenic switch of avascular, dormant microtumours. Appropriate inhibition of these stimulatory pathways may improve the recovery from surgery and prognosis in cancer patients.

\section{ACKNOWLEDGEMENTS}

Basic-FGF was kindly provided by Professor Gera Neufeld (Technion, Israel). Bovine endothelial cells were kindly provided by Professor Israel Vlodavsky (Hadassah Medical Center, Israel). This work was supported by a Research Career Development Award from the Israel Cancer Research Fund and by the Israel Science Foundation founded by the Israel Academy of Sciences and Humanities (to MN). MN is incumbent of Dr Phil Gold Career Development Chair in Cancer Research. RA is a recipient of a fellowship from the Charles Clore foundation.

\section{REFERENCES}

Abramovitch R, Meir G and Neeman M (1995) Neovascularization induced growth of implanted C6 glioma multicellular spheroids: magnetic resonance microimaging. Cancer Res 55: 1956-1962

Abramovitch R, Marikovsky M, Meir G and Neeman M (1998a) Stimulation of tumour angiogenesis by proximal wounds: spatial and temporal analysis by MRI. Br J Cancer 77: 440-447 
Abramovitch R, Neeman M, Reich R, Stein I, Keshet E, Abraham J, Solomon A and Marikovsky M (1998b). Intercellular communication between vascular smooth muscle and endothelial cells mediated by HB-EGF and VEGF. FEBS Lett 425: $441-447$

Abramovitch R, Frenkiel D and Neeman M (1998c) Analysis of subcutaneous angiogenesis by gradient echo magnetic resonance imaging. Magn Reson Med 39: $813-824$

Bogden AE, Moreau JP and Eden PA (1997) Proliferative response of human and animal tumours to surgical wounding of normal tissues: onset, duration and inhibition. Br J Cancer 75: 1021-1027

Deelman HT (1927) The part played by injury and repair in the development of cancer. Br Med J 1: 872

Dvorak HF, Brown LF, Detmar M and Dvorak AM (1995) Vascular permeability factor/vascular endothelial growth factor, microvascular hyperpermeability, and angiogenesis. Am J Pathol 146: 1029-1039

Frank S, Hubner G, Breier G, Longaker MT, Greenhalgh DG and Werner S (1995) Regulation of vascular endothelial growth factor expression in cultured keratinocytes. Implications for normal and impaired wound healing. $J$ Biol Chem 270: 12607-12613

Higashiyama S, Abraham JA, Miller J, Fiddes JC and Klagsbrun M (1991) A heparin-binding growth factor secreted by macrophage-like cells that is related to EGF. Science 251: 936-939

Libermann TA, Nusbaum HR, Razon N, Kris R, Lax I, Soreq H, Whittle N, Waterfield MD, Ullrich A and Schlessinger J (1985) Amplification and overexpression of the EGF receptor gene in primary human glioblastomas. Cell Sci 3(suppl): 161-172

Lynch SE (1991) Interactions of growth factors in tissue repair. Prog Clin Biol Res 365: $341-357$

Marikovsky M, Breuing K, Liu PY, Eriksson E, Higashiyama S, Farber P, Abraham J and Klagsbrun M (1993) Appearance of heparin-binding EGF-like growth factor in wound fluid as a response to injury. Proc Natl Acad Sci USA 90: 3889-3893

Marikovsky M, Vogt P, Eriksson E, Rubin JS, Taylor WG, Joachim S and Klagsbrun M (1996) Wound fluid-derived heparin-binding EGF-like growth factor (HB-EGF) is synergistic with insulin-like growth factor-I for Balb/MK keratinocyte proliferation. J Invest Dermatol 106: 616-621
Moulin V (1995) Growth factors in skin wound healing. Eur J Cell Biol 68: 1-7 Murthy SM, Goldschmidt RA, Rao LN, Ammirati M, Buchmann T and Scanlon EF (1989) The influence of surgical trauma on experimental metastasis. Cancer 64: $2035-2044$

Murthy MS, Summaria LJ, Miller RJ, Wyse TB, Goldschmidt RA and Scanlon EF (1991) Inhibition of tumor implantation at sites of trauma by plasminogen activators. Cancer 68: 1724-1730

O'Reilly MS, Holmgren L, Shing Y, Chen C, Rosenthal RA, Moses M, Lane WS, Cao Y, Sage EH and Folkman J (1994) Angiostatin: a novel angiogenesis inhibitor that mediates the suppression of metastases by a Lewis lung carcinoma. Cell 79: $315-328$

O'Reilly MS, Holmgren L, Chen C and Folkman J (1996) Angiostatin induces and sustains dormancy of human primary tumors in mice. Nature Med 2: 689-692

Pedersen PH, Ness GO, Engebraaten O, Bjerkvig R, Lillehaug JR and Laerum OD (1994) Heterogeneous response to the growth factors [EGF, PDGF (bb), TGFalpha, bFGF, IL-2] on glioma spheroid growth, migration and invasion. Int J Cancer 56: 255-261

Peoples GE, Blotnick S, Takahashi K, Freeman MR, Klagsbrun M and Eberlein TJ (1995) T lymphocytes that infiltrate tumors and atherosclerotic plaques produce heparin-binding epidermal growth factor-like growth factor and basic fibroblast growth factor: a potential pathologic role. Proc Natl Acad Sci USA 92: 6547-6251

Pollack IF, Randall MS, Kristofik MP, Kelly RH, Selker RG and Vertosick Jr FT (1991) Response of low-passage human malignant gliomas in vitro to stimulation and selective inhibition of growth factor-mediated pathways. J Neurosurg 75: 284-293

Schiffenbauer YS, Abramovitch R, Meir G, Nevo N, Holzinger M, Itin A, Keshet E and Neeman M (1997) Loss of ovarian function promotes angiogenesis in human ovarian carcinoma. Proc Natl Acad Sci USA 94: 13203-13208

Strawn LM, Mann E, Elliger SS, Chu LM, Germain LL, Niederfellner G, Ullrich A and Shawver LK (1994) Inhibition of glioma cell growth by a truncated platelet-derived growth factor-beta receptor. J Biol Chem 269: 21215-21222

Tsai JC, Goldman CK and Gillespie GY (1995) Vascular endothelial growth factor in human glioma cell lines: induced secretion by EGF, PDGF-BB, and bFGF. J Neurosurg 82: 864-873 